MANUELA PRADO LEITÃO

\title{
Desastres ambientais, resiliência e o direito
}

Tese de Doutorado

Orientadora: Professora Associada Doutora Patrícia Faga Iglecias Lemos

UNIVERSIDADE DE SÃO PAULO

FACULDADE DE DIREITO

São Paulo-SP

2017 



\section{Desastres ambientais, resiliência e o direito}

Tese apresentada à Banca Examinadora do Programa de Pós-Graduação em Direito, da Faculdade de Direito da Universidade de São Paulo, como exigência parcial para obtenção do título de Doutora em Direito, na área de concentração de Direito Civil, sob a orientação da Professora Associada Doutora Patrícia Faga Iglecias Lemos.

UNIVERSIDADE DE SÃO PAULO

FACULDADE DE DIREITO

\section{São Paulo-SP}


Catalogação da Publicação

Serviço de Biblioteca e Documentação

Faculdade de Direito da Universidade de São Paulo

Leitão, Manuela Prado

Desastres ambientais, resiliência e o direito /

Manuela Prado Leitão ; orientadora Patrícia Faga

Iglecias Lemos -- São Paulo, 2017.

249 p.

Tese (Doutorado - Programa de Pós-Graduação em Direito Civil) - Faculdade de Direito, Universidade de São Paulo, 2017.

1. Direito civil. 2. Direito ambiental. 3.

Desastres ambientais. 4. Resiliência. 5.

Responsabilidade civil. I. Lemos, Patrícia Faga

Iglecias, orient. II. Título. 
BANCA EXAMINADORA 

Aos meus pais, exemplos de amor, persistência e superação, professores da vida.

Ao José Pedro, companheiro de batalhas e conquistas, com amor.

Ao meu querido avô Honório, sempre orgulhoso da neta, in memoriam. 



\section{AGRADECIMENTOS}

Se é verdade que elaborar uma tese é um trabalho incessante e penoso, já que envolve criação, ineditismo e leitura à exaustão, a subjacente sensação de solidão é completamente equivocada. Ocorre que ao longo dessa empreitada estamos tão absortos no trabalho que parece que estamos sozinhos. Mas não estamos. Felizmente! E posso dizer que foi graças às pessoas que estiveram ao meu lado e me apoiaram ao longo dessa trajetória que eu consegui escrever, respirar e concluir esta tese.

Em primeiro lugar, gostaria de agradecer à minha orientadora, a quem admiro pessoal e profissionalmente, Professora Associada Doutora Patrícia Faga Iglecias Lemos, pela confiança nas minhas pesquisas desde o início da minha participação em seu grupo de estudos, até este momento, de tamanha importância para a minha vida acadêmica e de realização pessoal. As conversas sobre a tese foram decisivas para a sua materialização.

Em seguida, agradeço ao Professor Titular Doutor Fernando Scaff e ao Professor Associado Doutor Gustavo Mônaco pelas valiosas contribuições em minha banca de qualificação.

Meus agradecimentos destinam-se também aos meus pais e ao José Pedro pelo apoio incondicional, pelo incentivo e por todo o carinho envolvido, não apenas nessa trajetória, mas desde sempre. Meus pais, constantemente curiosos sobre o tema, estimularam-me, com segurança e doçura, a seguir em frente. Ao José Pedro, em particular, mesmo não sendo da área jurídica, agradeço pelas inúmeras conversas sobre o trabalho, que me trouxeram muitas luzes, e pela calma nos meus momentos de maior ansiedade. Seu companheirismo foi e continua sendo a razão do amor que cresce a cada dia.

Deixo o meu sincero agradecimento à equipe do GVlaw, com a qual tive o privilégio de dividir meus dias nos últimos anos. Além de colegas de trabalho, trouxeram um olhar acadêmico, ideias e leveza à empreitada, até os momentos finais. Agradeço em especial às gestoras da equipe, Maria Cecília e Karina, que sempre se mostraram pacientes com meus dilemas e dispostas a me ajudar.

É claro que não poderia deixar de mencionar meus colegas de GEAMA e do Doutorado da USP, com os quais também aprendi muito e cujas trocas de conhecimento e de artigos foram importantes.

Agradeço aos meus sogros, Teresa e José, aos demais familiares e amigos que procuraram entender o desafio que tinha pela frente e concordaram em adiar alguns cafés para colocar o papo em dia.

Por fim, à Jack, obrigada pela companhia e pelo seu afeto, simples e completo, durante essa jornada. 



\section{RESUMO}

LEITÃO, Manuela Prado. Desastres ambientais, resiliência e o direito. 249 p. Tese (Doutorado em Direito) - Faculdade de Direito da Universidade de São Paulo, São Paulo, 2017.

O enfrentamento dos desastres ambientais pelo direito, embora não seja recente, continua a impor-lhe desafios. Os desastres são classificados pela doutrina como tecnológicos ou naturais, a depender da existência ou não de intervenção humana. Todavia, constatou-se que até mesmo os desastres naturais apresentam alguma influência antrópica, revelando que as suas causas são múltiplas. No Brasil, a Política Nacional de Proteção e Defesa Civil (Lei n.12.608/2012) visa a conferir organicidade ao sistema de proteção e de gerenciamento de riscos de desastres entre os três entes da federação, evidenciando a necessidade de se adotarem medidas de prevenção e de precaução, além das ações de resposta. No plano internacional, o Marco de Sendai para a Redução de Riscos de Desastres é a declaração da Organização das Nações Unidas mais recente a tratar do tema. Ela evidencia conceitos como resiliência e risco para serem pensados de forma integrada e transversal às mais diversas políticas públicas. Sua adoção deve ser considerada na aplicação de leis e de princípios de direito ambiental. Esses conceitos impõem uma releitura também das funções preventiva e reparatória da responsabilidade civil, nomeadamente do princípio da reparação integral, em prol de uma reparação resiliente, que requer a incorporação do risco no conceito de dano. Isso permite, ademais, repensar a aplicação do artigo 944, parágrafo único, do Código Civil, para o caso de desproporção entre a culpa do ofensor e os danos causados pelo desastre ambiental.

Palavras-chave: Direito civil. Direito ambiental. Desastres ambientais. Riscos ambientais. Resiliência. Responsabilidade civil. Princípio da reparação integral. 


\begin{abstract}
LEITÃO, Manuela Prado. Disasters, resilience and the law. 249 p. Thesis (Law Doctorate) - University of São Paulo Law School, São Paulo, 2017.

Disasters are not a new subject to law, nevertheless they continue to raise challenges. Disasters are classified either as technological or natural depending on the presence of human interference. However, it is possible to attest that even natural disasters have some anthropic influence, which demonstrates that disasters have multiple causes. The National Civil Defense Policy in Brazil (Law n. 12.608/2012) aims to organize the duties and responsibilities of each of the three levels of the federation in regard to risk management and disaster protection, displaying the need to adopt preventive and precautionary measures beyond that of disaster responses. Internationally, the United Nations Sendai Framework for Disaster Risk Reduction is the most recent declaration to bring forward concepts like resilience and risk, putting them at the cornerstone of the most diverse public policies. Its adoption should be considered when enforcing environmental laws and principles. These concepts impose a review of the preventive and reparatory functions of tort in benefit of a resilient recovery, which requires the incorporation of risk in the concept of harm. It also invokes a reflection about the Brazilian Civil Code rule that allows judges to reduce indemnification in the case of disproportion between the offender's fault and the harm caused by the disaster.
\end{abstract}

Key-words: Civil law. Environmental law. Disasters. Risks. Resilience. Tort. Recovery. 


\section{RESUMÉE}

LEITÃO, Manuela Prado. Les catastrophes, la résilience et le droit. 249 p. Thèse (Doctorat en Droit) - Faculté de Droit de l’Université de São Paulo, São Paulo, 2017.

Les catastrophes ne sont pas nouvelles pour le droit, mais elles continuent à l'imposer des défis. Les catastrophes sont classées par la doctrine comme technologiques ou naturelles, en fonction d'intervention humaine. Néanmoins, même les catastrophes naturelles ont l'influence humaine, ce que révèle que les causes des catastrophes sont multiples. Au Brésil, la Politique Nationale de la Protection et de la Défense Civile (Loi n. 12.608/2012) organise le système de protection et de gestion des risques de catastrophe entre les trois membres de la fédération, en soulignant la nécessité d'adopter des mesures de prévention et de précaution, en plus des actions de réponse. Au niveau international, Le Cadre d'Action de Sendai pour la Réduction des Risques de Catastrophe est la plus récente déclaration des Nations Unies sur le thème. Il met en évidence des concepts tels que la résilience et le risque d'une manière intégrée et transversale à plusieurs politiques publiques. Son adoption devrait être pris en compte dans l'application des lois et des principes de droit de l'environnement. Ces concepts sont nécessaires aussi pour une réinterprétation des fonctions préventives et curatives de la responsabilité, y compris le principe de la réparation intégrale, en faveur d'une réparation résiliente. Ça nécessite la prise en compte du risque dans la notion de dommage. Cela permet, en outre, de repenser l'application de la règle du Code Civil Brésilien qui permet que le juge réduise l'indemnisation en cas de disproportion entre la faute du défendeur et le dommage causé par la catastrophe.

Mots-clés : Droit civil. Droit de l'environnement. Catastrophes. Risques. Résilience. Responsabilité civile. Principe de la réparation intégrale. 

Vinde pois, contemplai ruinas desoladas, restos, farrapos só, cinzas desventuradas, os meninos e as mães, os seus corpos em pilhas, membros ao deus-dará no mármore em estilhas, desgraçados cem mil que a terra já devora, em sangue, a espedaçar-se, e a palpitar embora, que soterrados são, nenhum socorro atinam e em horrível tormento os tristes dias finam!

Voltaire, O poema sobre o desastre de Lisboa, (1756). 



\section{SUMÁRIO}

INTRODUÇÃO. 19

\section{ONDE ESTAMOS? OS DESASTRES AMBIENTAIS E ALGUNS}

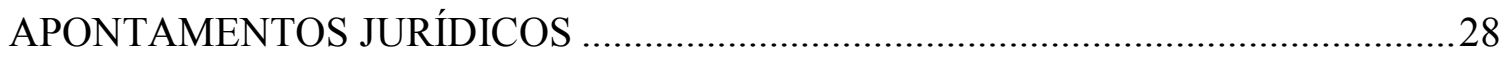

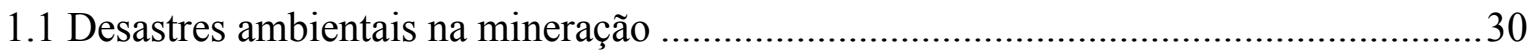

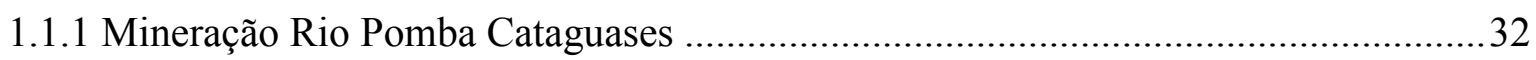

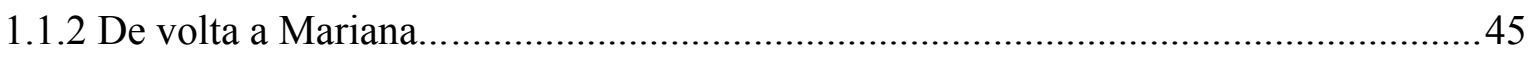

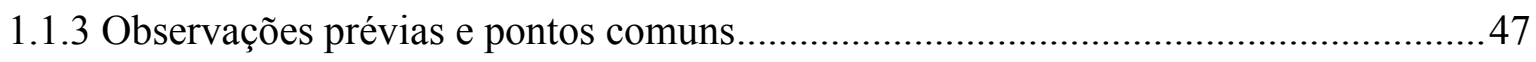

1.2 Desastres: tentativas de compreensão (jurídica) do conceito .......................................49

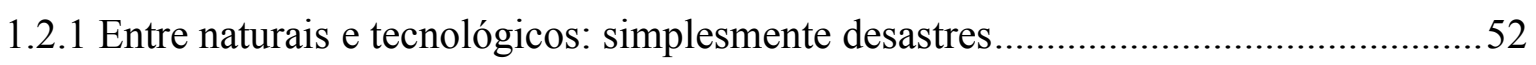

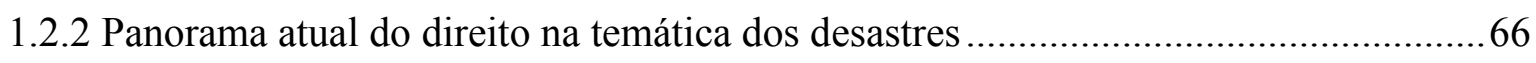

1.3 A Política Nacional de Proteção e Defesa Civil: uma política pública em construção .68

1.3.1 Definições e classificações normativas.................................................................... 75

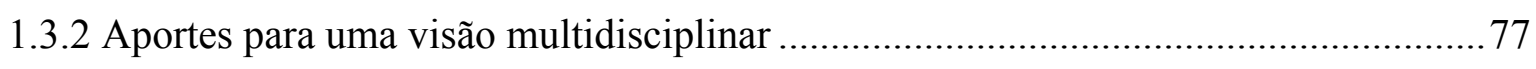

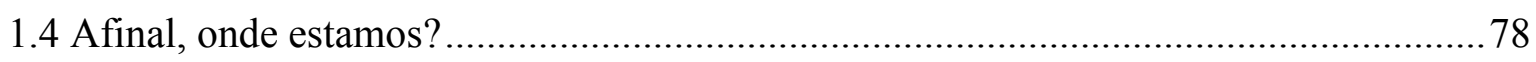

2 PARA ONDE VAMOS? O DIREITO ENTRE A VULNERABILIDADE,

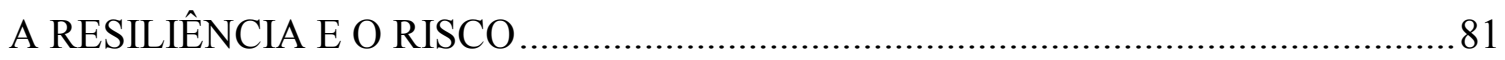

2.1 A mobilização internacional: de Yokohama a Sendai ................................................ 82

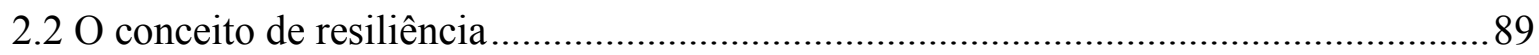

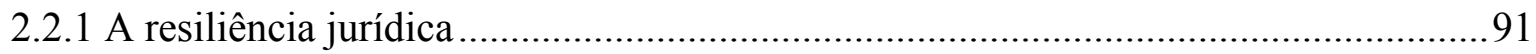

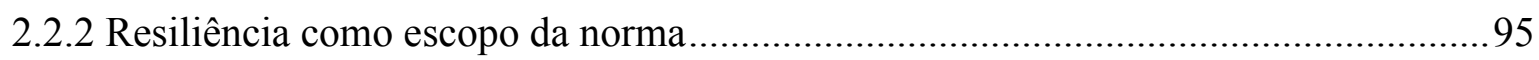

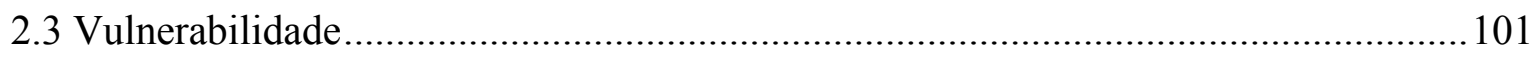

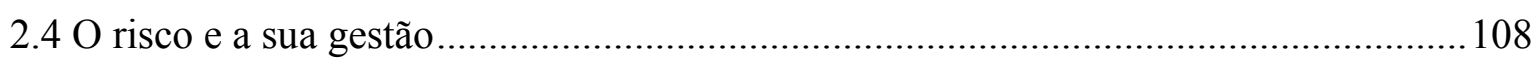

2.4.1 A incorporação do risco pela norma .................................................................... 116

2.4.2 Breves considerações sobre a norma norte-americana ......................................... 117

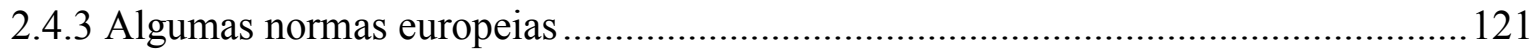

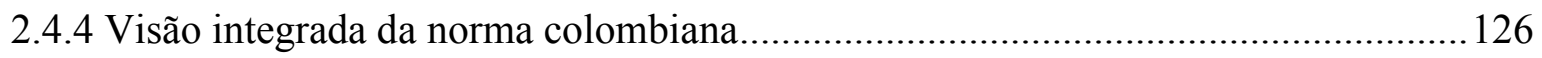

2.4.5 Brasil: Política Nacional de Segurança de Barragens e o risco ............................... 128

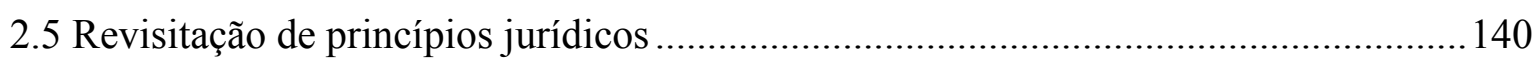

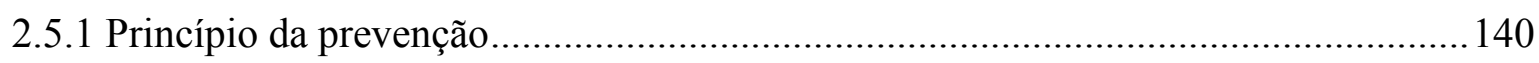

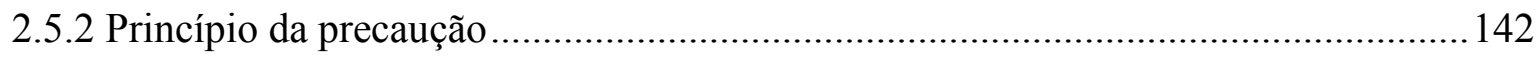

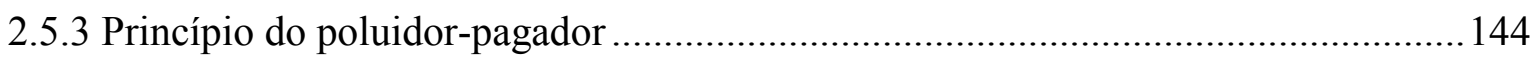

2.5.4 Princípios da informação e da participação ................................................................ 146

2.5.5 Princípio do desenvolvimento sustentável........................................................ 149 
2.5.6 Princípio da responsabilidade compartilhada

2.5.7 Princípio da função socioambiental da propriedade ...............................................152

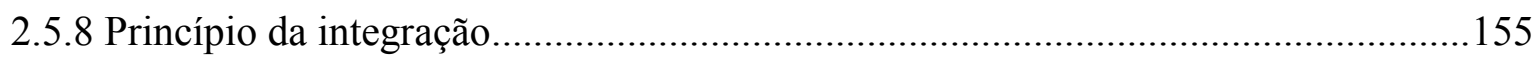

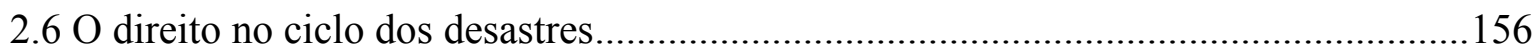

3 COMO VAMOS? A RESPONSABILIDADE CIVIL EM PROL DA RESILIÊNCIA.161

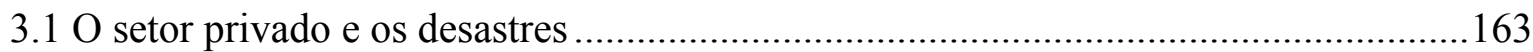

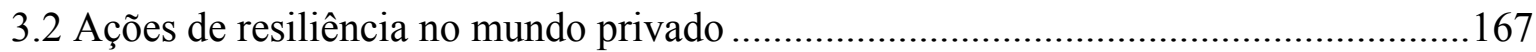

3.3 A responsabilidade civil como instrumento de resiliência...........................................169

3.3.1 Caso fortuito ou força maior: conceitos ultrapassados? ..........................................171

3.3.2 A revisitação das funções da responsabilidade civil ...............................................177

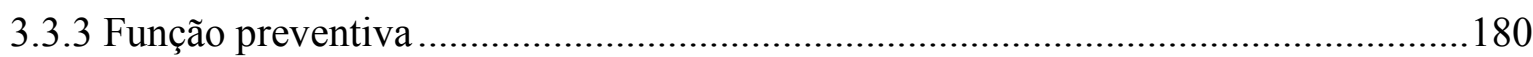

3.3.4 A reparação integral como reparação resiliente ......................................................192

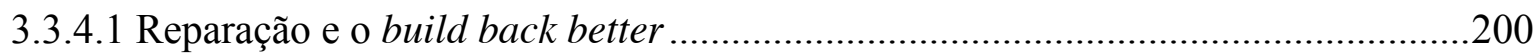

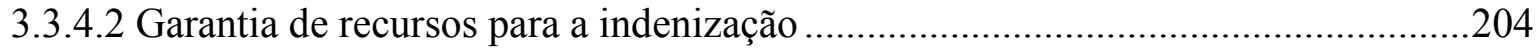

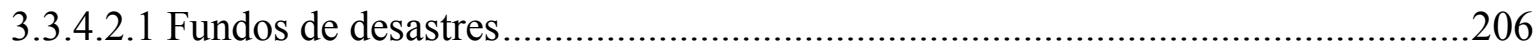

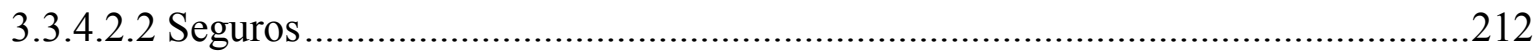

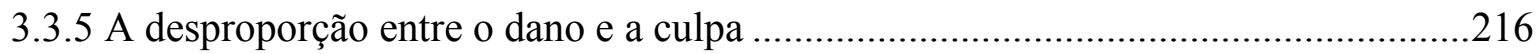

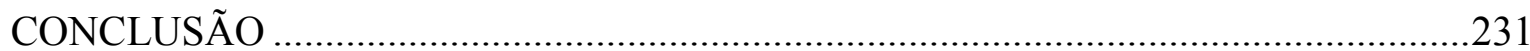

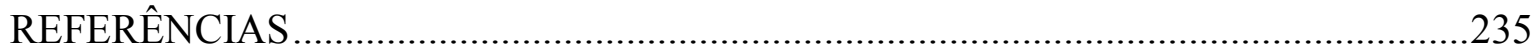




\section{INTRODUÇÃO}

No final da década de 1970, o filósofo Hans Jonas ${ }^{1}$ publicou obra em que trouxe uma reflexão sobre uma ética para a civilização tecnológica. Crê o autor que o avanço técnico-industrial e os riscos criados pelo ser humano, em função da exacerbação do consumo e da dominação da técnica sobre a natureza, colocam em xeque a sua existência, sendo necessário indagar os limites à humanidade para colocar a si própria em risco: "Pode-se discutir a respeito do direito individual ao suicídio, mas não a respeito do direito de suicídio por parte da humanidade", afirma o filósofo. ${ }^{2}$

Em uma visão pautada pelo medo e por um “prognóstico do desastre”, Hans Jonas afirma que não se faz um cálculo de longo prazo sobre os riscos presentes, deixando o futuro à sua própria sorte. Um novo paradigma filosófico, porém, passaria a conferir maior importância aos efeitos futuros do agir humano no presente, invocando um novo princípio ético, um princípio que determina um dever de cuidado em relação ao futuro.

Nessa nova dimensão ética, Hans Jonas sustenta a incerteza obriga o ser humano a uma real responsabilidade pelo porvir, na qual a prudência se torna o cerne de todo o agir. Para tanto, é preciso desapegar da lógica tradicional de que a cada direito corresponde um dever e a cada dever um direito, no momento presente, tendo em vista que o dever com o futuro não terá a sua reciprocidade no momento atual. ${ }^{3}$

Nessa esteira de raciocínio, o filósofo defende que não se trata de garantir os direitos das pessoas no futuro, mas sim de lhes conceder a existência e a possibilidade de exercerem os direitos conforme a sua época. Em contraposição a esse direito de existir, há o poder do indivíduo - ou da humanidade - no presente, que exerce alguma influência sobre o futuro. Surge uma responsabilidade que olha para a frente porque se volta para o objeto que reivindica o agir do ser humano - a responsabilidade pelo bem-estar social, seguindo o exemplo fornecido pelo autor, ou a responsabilidade pela preservação ambiental, que acrescentamos - e não a responsabilidade pelas consequências de uma

\footnotetext{
${ }^{1}$ JONAS, Hans. O princípio responsabilidade: ensaio de uma ética para a civilização tecnológica. Tradução de Marijane Lisboa e Luiz Barros Montez. Rio de Janeiro: Contraponto; Ed. PUC-Rio, 2006. p. 235-236.

${ }^{2}$ Ibidem, p. 86.

${ }^{3}$ Ibidem, p. $79-89$.
} 
conduta pretérita. É como se as gerações futuras dependessem das ações da geração presente e é a conduta desta que influencia a existência daquelas. ${ }^{4}$

Em sua concepção, o princípio responsabilidade contrapõe-se ao princípio esperança, o qual pressupõe a realização de ações com certeza, conforme esperado e desejado, em prol de algo benéfico para o futuro. O princípio responsabilidade se pauta pelo medo que, distintamente da covardia, considera a incerteza e convida ao agir diante dela, porque se teme que algo aconteça com o objeto vulnerável. "A responsabilidade é o cuidado reconhecido como obrigação em relação a um outro ser, que se torna 'preocupação' quando há uma ameaça à sua vulnerabilidade."5

Em uma visão oposta e intrigante, Cass Sunstein, em obra datada do ano de 2005, questiona o "direito do medo", ao argumentar que a incerteza diante de riscos resulta em más concepções dos reais efeitos da ação humana sobre o meio que o cerca, pois induz a um agir irracional - ou pouco racional. Para o autor, procurar atuar diante de toda incerteza, em atenção ao princípio da precaução, pode exacerbar riscos mínimos e negligenciar riscos graves, já que a abertura a uma construção democrática da percepção do risco não incorpora os seus reais elementos, mas principalmente a memória emocional das pessoas. Estas, por sua vez, tendem a apresentar uma "miopia", ao focarem em ações de curto prazo e relegarem o longo prazo, além de a maioria das pessoas serem otimistas quanto ao futuro e quanto às suas condutas, pensando que são mais prudentes que as demais ao seu redor. ${ }^{6}$

O medo, na acepção do autor, tende a ser maior diante de riscos novos e desconhecidos do que de riscos conhecidos e incorporados no cotidiano, ainda que sejam riscos graves, como é o caso de acidentes automobilísticos. Há também uma ideia de que a natureza é de certo modo harmônica e benevolente, o que precisa ser refutado. Afinal, nem tudo que é completamente natural é seguro, basta pensar na exposição à radiação solar, apta a ser causa do desenvolvimento de câncer de pele. Assim, é preciso ter em mente que a interferência humana sobre a natureza abala seu sistema natural de funcionamento e, com

\footnotetext{
${ }^{4}$ JONAS, Hans, O princípio responsabilidade: ensaio de uma ética para a civilização tecnológica, cit., p. 91 94; 167 et seq.

${ }^{5}$ Ibidem, p. 351-352.

${ }^{6}$ SUNSTEIN, Cass R. Laws of fear: beyond the precautionary principle. Cambridge, UK; New York: Cambridge University Press, 2005. p. 51-59.
} 
isso, cria riscos, mas é salutar ponderar também que os benefícios criados à vida, de modo mais amplo, não são insignificantes e nem todos os riscos acarretam perdas insuportáveis. ${ }^{7}$

A despeito de criticar enfaticamente o princípio da precaução, Cass Sunstein reconhece que é preciso tomar precauções, para o que propõe uma releitura do princípio, para acabar com a cultura do medo sobre o futuro. O medo paralisa a ação, engessando a produção e o avanço tecnológico. Em contrapartida, é preciso que os gestores de risco, diante de incertezas de catástrofes, adotem medidas de contenção e de mitigação desses riscos, desde que os custos associados não sejam excessivos a ponto de prejudicarem a qualidade de vida ou desviarem recursos de outras áreas mais necessitadas. É preciso, antes de mais nada, tomar em conta os riscos sociais de modo global, para verificar se a concepção de medidas que evitem desastres não são por si só potencializadoras de riscos também de desastres. É preciso - segundo o autor - que sejam desenvolvidas margens de segurança para os riscos, mas elas devem variar de tamanho e intensidade em função do tipo de riscos, da potencialidade dos danos e, sobretudo, dos custos associados. ${ }^{8}$

Cass Sunstein sobrevaloriza o presente em relação ao futuro e procura negar aquilo que chama de restrições injustificadas sobre a vida privada, o que, para ele, ocorre pela exacerbação do medo, com a aplicação genérica do princípio da precaução ${ }^{9}$. Essa visão de negação do princípio é porém largamente combatida por Maria da Glória Garcia. A autora rebate os argumentos de Cass Sunstein e repisa que o princípio da precaução se insere na cultura ética, filosófica e política que orienta e renova o atual discurso jurídico, bem como inova na criatividade da atuação humana em prol do bem-estar das futuras gerações. Reconhece que toda decisão, mesmo a precaucional, envolve riscos, pois há o desconhecimento quanto ao futuro, ao que há de melhor para ele e o resultado das sinergias, bem como a relação entre a intencionalidade da ação e seu resultado efetivo ${ }^{10}$. Nesse sentido, Maria da Gloria afirma que:

\footnotetext{
${ }^{7}$ SUNSTEIN, Cass R., Laws of fear: beyond the precautionary principle, cit., p. 43-45.

${ }^{8}$ Ibidem, p. 109-119.

${ }^{9}$ Ibidem, p. 222-223.

${ }^{10}$ GARCIA, Maria da Glória F. P. D. princípio da precaução: lei do medo ou razão de esperança? In: CORREIA, Fernando Alves; MACHADO, Jónatas Eduardo Mendes; LOUREIRO, João Carlos Simões Gonçalves (Orgs.). Estudos em homenagem ao prof. doutor José Gomes Canotilho: responsabilidade entre passado e futuro. Coimbra: Coimbra Editora, 2012. v. 1, p. 323-329.
} 
Significa isto que a actuação que, em apelo a uma situação que clama a obediência ao princípio da precaução, o cumpra, nos seus exactos termos, isto é, a actuação jurídica que seja a resposta precaucional à situação de risco assume o que deve ter-se por justo, o que deve ter-se por certo. Mas não o que é certo ou é justo. ${ }^{11}$

A partir dessas reflexões filosóficas, ensaiamos um estudo que busca debater o direito na perspectiva dos desastres ambientais futuros, olhando para os riscos presentes. Sabemos que o direito não é capaz de controlar os desastres. Adotar essa visão corresponderia à sobrevalorização da ciência jurídica, em detrimento de outras ciências que, quiçá, estão mais próximas da inovação para o enfrentamento dos riscos presentes e dos danos futuros. Inovação, aliás, é um desafio sobre o qual o direito se debruça, a começar pela elaboração de leis que não acompanham a velocidade dos acontecimentos sociais e de uma responsabilidade civil voltada, sobretudo, para o passado...

Não faremos uma análise filosófica do direito, como fizeram os pensadores acima, mas provocados por suas reflexões e pelos casos práticos noticiados no nosso cotidiano, procuraremos fornecer pequenas bases para a revisitação de determinados instrumentos jurídicos, nomeadamente princípios de direito civil-ambiental e conceitos relacionados à responsabilidade civil, para enfrentar essa temática já antiga, mas que a cada dia impõe a dinamicidade dos seus desafios. De Chernobyl a Fukushima e Mariana, muito se construiu no direito ambiental e muito já se preveniu, mas os desastres continuam a ocorrer e, possivelmente, voltarão no futuro.

Nossa intenção é compreender a lógica sobre a qual os riscos são percebidos e estruturados, bem como os elementos que estão diretamente relacionados a eles - a vulnerabilidade e a resiliência - para repensar alguns instrumentos jurídicos, no sentido de alertar para um futuro que envolva desastres ambientais, ao mesmo tempo que afaste o "medo" ou uma lógica pessimista tão invocada pelos pensadores supracitados, para conceber o adequado enfrentamento dos riscos socioambientais e de seus potenciais danos que se mostrem inevitáveis.

Não pensamos que, para isso, devamos deixar a natureza intocada ou jogar um ônus excessivo sobre o avanço tecnológico, mas sim estimular o desenvolvimento que seja

${ }^{11}$ GARCIA, Maria da Glória F. P. D., Princípio da precaução: lei do medo ou razão de esperança?, in Estudos em homenagem ao prof. doutor José Gomes Canotilho: responsabilidade entre passado e futuro, cit., v. 1, p. 329. 
sustentável e resiliente. Partimos de uma premissa otimista de que, com o princípio responsabilidade lançado por Hans Jonas e a ponderação da racionalidade de Cass Sunstein, cheguemos ao ponto ótimo, em que o risco de desastres ambientais seja melhor incorporado pelos seus gestores, tornando mais escassa a violação ao meio ambiente saudável e equilibrado e à dignidade da pessoa humana.

Salientamos que o foco de nossa análise serão os desastres ambientais em seu conceito mais amplo, de origem climática ou não, que podem abarcar aqueles oriundos de fenômenos naturais, como precipitações fortes, inundações, erupções vulcânicas, terremotos, ciclones etc., até os desastres no meio ambiente e social causados por acidentes tecnológicos, ou, ainda, os desastres que resultam da interação antrópica e natural.

A razão de abordarmos todas essas espécies de desastres ambientais consiste no fato de não procurarmos estabelecer um regime jurídico a partir de definições dos desastres pelas suas causas, de forma preestabelecida e taxativa, mas sim pelas suas características e seus efeitos. Veremos que os desastres ambientais decorrem da interação entre inúmeras causas e concausas, de origem humana e natural. Abordaremos a temática sob o enfoque da prevenção, da precaução e da resiliência, buscando entender, primeiramente, as circunstâncias que contribuem para os desastres ambientais para, em seguida, indagarmos de que modo os instrumentos jurídicos podem auxiliar uma adequada gestão dos riscos dos desastres.

Nesse diapasão, e refletindo a nossa indignação quanto à ocorrência de desastres ambientais em pleno século XXI, no auge de tamanho desenvolvimento tecnológico - ou por causa dele -, que deveria ser destinado à prevenção e ao monitoramento de riscos, tomamos como ponto de partida casos reais recentes e desenvolvemos em cima deles a nossa crítica e reflexão sobre o papel do direito - em especial da responsabilidade civil na construção de resiliência ambiental.

O tema da resiliência é transversal a diversas ciências e, no contexto jurídico, aos poucos ganha espaço em declarações internacionais e na elaboração de políticas públicas. Em relação aos riscos, embora as iniciativas para o seu tratamento sob a perspectiva dos desastres ambientais e da construção de resiliência sejam oriundas de discussões entre Estados, fazendo todo o sentido que estejam imbuídas no seio das leis e das políticas 
públicas de curto, médio e longo prazo, não podemos esquecer que o setor privado também é ator que cria e gera riscos socioambientais em seu cotidiano, seja pela execução de sua atividade, seja no exercício de sua propriedade.

A metodologia que utilizamos centra-se basicamente em revisão de literatura, nacional e internacional, sobre o tratamento jurídico dos desastres e das catástrofes naturais e da responsabilidade civil preventiva, bem como análise legislativa, citando declarações internacionais celebradas no âmbito da Organização das Nações Unidas, normas brasileiras e estrangeiras, nomeadamente dos Estados Unidos e da União Europeia, em que a temática parece estar desenvolvida há mais tempo. Citamos, em algumas passagens, a lei da Colômbia, pois no contexto sul-americano, esse foi o primeiro país a trazer de forma sistematizada e integrada uma política de gestão de riscos de desastres - ao invés de uma gestão puramente de desastres.

Apesar de o nosso trabalho ter por base majoritária essa literatura jurídica, utilizamos alguns textos de outras ciências para fundamentar e compreender melhor os conceitos que apresentamos. Também recorremos a julgados do Superior Tribunal de Justiça, que fixaram entendimento sobre alguns dos argumentos a que fazemos alusão em nosso texto, tanto para demonstrar - e criticar - algumas das premissas ali adotadas, quanto para embasar as nossas convicções.

Verificamos que a literatura nacional ainda é escassa quanto ao papel do setor privado no tema dos desastres ambientais e da resiliência e é por essa razão que procuraremos desenvolver nossa tese colocando-o no centro de nossa análise. As conclusões aqui alcançadas não se restringirão a ele, algumas delas poderão eventualmente ser pensadas para o Poder Público, de acordo com as particularidades de seu regime jurídico, mas não abordaremos essa possibilidade em nosso trabalho, pois isso por si só abriria espaço para outra tese.

Assim, no Capítulo 1, procuraremos apresentar o cenário atual, ou, melhor dizendo, o "estado da arte" jurídico para um direito dos desastres. Tomaremos como ponto de partida o recente acidente ocorrido com a ruptura da barragem de Fundão, no Município de Mariana, em Minas Gerais, considerado o maior desastre ambiental brasileiro até os dias atuais. Existe um largo desenvolvimento doutrinário e jurisprudencial acerca da imputação 
de responsabilidade ao poluidor no caso de desastres tecnológicos, como é classificado pela doutrina, lastreada em responsabilidade objetiva e de risco integral, flexibilizando-se o nexo causal, a fim de garantir a responsabilização, para fins de reparação.

Ainda nessa parte, discorreremos brevemente sobre a evolução normativa da Política Nacional de Proteção e Defesa Civil, que pretendeu instituir um novo marco legal sobre o tratamento dos desastres ambientais sob a perspectiva da prevenção e organizar as competências dos entes da federação. Veremos a influência dessa lei sobre outros diplomas normativos do ordenamento jurídico brasileiro relacionados sobretudo com o meio ambiente urbano e uso e ocupação do solo.

Vale ressaltar que optamos por iniciar nosso trabalho com alguns casos concretos envolvendo acidentes com barragens porque, além de facilitar a relação feita pelo leitor entre a tese e o que encontra na mídia, pensar o direito a partir da prática transparece o fato de as soluções jurídicas de que dispõe o direito hoje se revelam insuficientes. No entanto, a despeito de o caso de Mariana e, notadamente, precedentes de acidentes ambientais envolvendo barragens serem constantemente invocados ao longo da tese, não é nossa pretensão desenvolver um estudo de caso pormenorizado. A ideia é apenas usar esses casos como pano de fundo de nossa narrativa, pinçando pontos que podem ser repensados a partir de outra lógica que permeia o direito, ao enaltecer o risco, a vulnerabilidade e a resiliência.

Esses três conceitos serão pormenorizados no Capítulo 2, em que trataremos da evolução das declarações internacionais elaboradas no âmbito da Organização das Nações Unidas em torno do tema dos desastres ambientais. Faremos referência expressa ao Marco de Ação de Hyogo para o período de 2005-2015 e ao Marco de Sendai, com diretrizes para o período de 2015-2030. Procuraremos transparecer a mudança de paradigma ocorrida na evolução dessas declarações, que deixam de abordar os desastres sob a perspectiva exclusiva da resposta para focarem também na gestão do risco, na prevenção e na construção de uma resiliência ambiental.

Como resultado dessa evolução, lançaremos luz sobre o modo pelo qual o direito pode se valer desses conceitos para atingir o objetivo de mitigação de futuros desastres. Levantaremos o debate de como eles poderão gerar uma nova visão de alguns dos mais 
importantes princípios de direito ambiental, a fim de influenciar a tomada de decisão dos setores público e privado, e até mesmo do legislador. Uma visão mais holística dos desastres gera uma nova forma de conceber um "direito dos desastres", como já procurou fazer Daniel Farber ${ }^{12}$ e, entre nós, Délton Winter de Carvalho e Fernanda Damacena. ${ }^{13}$

Por fim, no Capítulo 3 serão lançadas hipóteses ainda incipientes - e sem a pretensão se serem apresentadas todas as respectivas conclusões no presente trabalho - de como o nosso ordenamento jurídico poderia alcançar os objetivos de resiliência aos desastres ambientais, em especial por meio de ações do setor privado, e de modo que este se sinta estimulado ao desenvolvimento de ações preventivas. Nesse diapasão, lançaremos ideias de qual poderia ser o papel da responsabilidade civil ambiental do agente privado, para incorporar os objetivos traçados pelo "direito dos desastres".

De forma mais concreta, iniciaremos nessa última parte um debate sobre uma releitura do princípio da reparação integral, para que seja uma reparação resiliente e conferiremos uma nova interpretação à culpa estampada no artigo 944, parágrafo único, do Código Civil de 2002, com o objetivo de torná-la um atrativo econômico para o setor privado engajar-se no desenvolvimento de atividades com gestão controlada de riscos. Sabemos que, historicamente, a culpa ganhou novos contornos e configurações, tendo sido desconsiderada em hipóteses claramente estabelecidas pelo ordenamento como casos de responsabilidade objetiva e de prevalência da teoria do risco. É precisamente o que ocorre em sede de danos ambientais.

Contudo, ao pensarmos em uma responsabilidade de cunho eminentemente preventivo, é preciso reavaliar a culpa como elemento indutor de medidas preventivas, o que, aliás, é o cerne de uma responsabilidade civil que visa ao futuro incerto e desconhecido, lastreado no risco. Ressaltamos, desde já, que não é nossa intenção abordar o tema da culpa ou mesmo da responsabilidade civil em extensão desde as suas origens, ainda que façamos a remissão a elas em algumas passagens. Nosso objetivo é compreender o sentido da sua evolução e das suas funções para pensarmos em novas configurações.

\footnotetext{
${ }^{12}$ FARBER, Daniel A. Introduction: legal scholarship, the disaster cycle, and the Fukushima accident. Duke Environmental Law \& Policy Forum, Durham, NC, v. 23, No. 1, p. 1-21, Fall 2012. Disponível em: $<$ http://scholarship.law.duke.edu/delpf/vol23/iss1/1>. Acesso em: 02 nov. 2016.

13 CARVAlHO, Délton Winter de; DAMACENA, Fernanda Dalla Libera. Direito dos desastres. Porto Alegre: Livraria do Advogado, 2013.
} 
Cada um desses aspectos a serem discutidos em nosso trabalho não se encerra nas conclusões aqui apresentadas. Ao contrário, pretendemos que sejam pontos para reanálise e aprofundamento, tanto por nós, quanto por quaisquer interessados nos temas de desastres ambientais e de resiliência. Afinal, o direito contemporâneo com olhar no futuro deve estar aberto a constantes mudanças na interpretação e adaptação de seus instrumentos aos riscos endógenos e exógenos, tendo como desafio o seu objetivo de segurança jurídica, de pacificação social e de proteção de direitos fundamentais. Em outras palavras, o direito, em si mesmo, deve ser resiliente. 


\section{CONCLUSÃO}

Ao longo do presente trabalho, partimos de um ponto "onde estamos" em matéria de desastres ambientais, ou seja, um panorama sobre as circunstâncias fáticas e jurídicas que circundam o tema. Vimos, como panorama de fundo de nosso trabalho, desastres com barragens ocorridos no Brasil nos últimos tempos, destacando aquele ocorrido em Mariana, Minas Gerais, em 5 de novembro de 2015. Apresentamos dados coletados de bases internacionais sobre a incidência de desastres no mundo, divididos em naturais, tecnológicos e de acordo com a região de ocorrência.

Procuramos enfrentar a problemática do conceito de desastre, que a doutrina tende a classificar em tecnológico, quando sua causa for exclusivamente humana; natural, quando ela corresponder a um fenômeno da natureza; e híbrido, quando ambos fatores contribuírem para a causa do desastre. Afirmamos que os estudos mais recentes na temática dos desastres revelam que eles não são resultado de apenas uma causa, mas sim uma multiplicidade delas e de um processo. Assim, nem mesmo os atos naturais podem ser exclusivamente naturais, já que sempre haverá alguma ingerência antrópica como concausa.

A partir da análise desses dados e dos julgados sobre o tema, evidenciamos os instrumentos jurídicos atualmente existentes em torno da responsabilidade civil ambiental e suas principais características para enfrentar os desafios que os desastres ambientais impõem à responsabilização dos poluidores e da reparação dos danos. Após essa exposição, concluímos que apesar desses instrumentos se revelarem bastante úteis atualmente, nem sempre são suficientes para acompanhar a evolução da temática, que se centra numa perspectiva de gerenciar riscos, ao invés de exclusivamente preocupar-se com os danos.

Nesse sentido, discorremos sobre a Política Nacional de Proteção e Defesa Civil como norma que visa a conferir organicidade ao sistema de proteção e gerenciamento de riscos entre as três esferas da federação, bem como adotar um novo marco legal em tema de desastres, para priorizar ações de prevenção e de precaução sobre medidas meramente de resposta. 
Em seguida, verificamos "para onde vamos", ou seja, os caminhos que se desenham no plano internacional e que demandam um olhar sobre a vulnerabilidade, a resiliência e o risco. Esses três conceitos devem ser pensados de forma integrada e transversal às mais diversas políticas públicas, para que haja um desenvolvimento amplo e holístico de ações, visando à mitigação de riscos de desastres.

Abordamos a relevância da introdução do conceito de resiliência no ordenamento jurídico. A resiliência deve ser não apenas ecológica, como indicam as origens do conceito na biologia, mas também e sobretudo ambiental, isto é, apta a permitir a recuperação do meio ecológico, dos bens ambientais e das populações vulneráveis, educando-as para o preparo ao desastre, à resistência e à adaptação a ele, bem como às alternativas de desenvolvimento econômico das comunidades, para que este não seja integralmente paralisado. A resiliência se revela como objetivo essencial, no contexto urbano, para o direito à cidade e, numa abordagem mais ampla, à efetivação de direitos relacionados à sustentabilidade inter e intrageracional.

Vimos também que a expressão "resiliência" ainda é escassa na legislação brasileira. Contudo, é possível inferi-la na aplicação de leis ambientais e de princípios de direito ambiental, para tê-la como escopo da norma. Até mesmo o direito deve cada vez mais se apresentar resiliente e adaptável às demandas ambientais emergentes, mas ainda incertas, como reflete a problemática das mudanças climáticas.

Com base nas premissas trazidas pelo Marco de Sendai e pelas definições a que chegamos ao longo do trabalho, buscamos ensaiar um caminho sobre "como vamos", para alcançarmos os objetivos traçados internacionalmente em prol da resiliência e mitigação de desastres. Assim, consideramos que os deveres relacionados à prevenção e à precaução, que envolvem a gestão adequada de riscos, a mitigação de vulnerabilidades e o fomento da resiliência não se restringem aos entes públicos, ainda que a obrigatoriedade seja expressa para eles na Política Nacional de Proteção e Defesa Civil. Esses deveres também se estendem ao setor privado por interpretação sistêmica, a partir da matriz constitucional que estabelece um direito e um dever de todos relativamente ao meio ambiente saudável e equilibrado. 
Existe uma série de ações que o setor privado pode desenvolver para o planejamento de uma adequada gestão de riscos, a fim de se mitigarem danos e, principalmente, lidar com causas e concausas de desastres ambientais. Citamos, dentre outros, mecanismos de monitoramento, de construção de infraestrutura com materiais resistentes, criação de infraestrutura verde, educação ambiental, governança corporativa, programas de certificação e de compliance ambiental.

Apesar de essas medidas serem mais facilmente adotadas como incentivos econômicos e fiscais, entendemos que elas também devem ser consideradas pela responsabilidade civil. Assim, quando forem determinadas pela norma, seu descumprimento ensejará responsabilidade pela violação de um interesse juridicamente protegido.

De outro modo, quando essas medidas forem mais protetivas do que estabelece a norma e forem adotadas espontaneamente pelo setor privado, ponderamos que, ainda que ocorra um desastre ambiental, essa conduta deve ser considerada no momento da aferição do valor da compensação, uma vez que, no campo da gestão de riscos, ela poderá ter propiciado uma mitigação da perturbação à qualidade de vida e ao meio ambiente saudável e equilibrado.

Nesse sentido, entendemos que a culpa aferida objetivamente como contribuição causal de um dano - no caso, desastres ambientais - poderá ser considerada para redução do valor da indenização, em juízo de equidade, quando a conduta do agente houver contribuído para a mitigação de riscos e para o fortalecimento de resiliência ambiental, refletindo excessiva desproporção entre culpa e dano.

Essa conclusão nos parece possível diante de uma reconfiguração do conceito de dano ambiental, para também incorporar o risco (de desastre). Afinal, o Marco de Sendai passa a exigir a resiliência também na reparação, por meio do build back better, ou seja, de uma recuperação do estado anterior ao dano acrescido de mitigação de riscos. Se a reparação se mede pela extensão do dano, isso significa que o risco passa a integrar o dano, no bojo do conceito de dano social. 
Além disso, essa nova perspectiva contribui para a revisitação do princípio da reparação integral no caso de desastres, o qual deverá abraçar a ideia de reparação resiliente, isto é, aquela que restaura o equilíbrio natural e socioeconômico, mitiga riscos e que também apresenta uma compensação financeira, para fins de satisfação dos interesses violados da coletividade. Essa reparação pode ocorrer com o auxílio de seguros contra desastres ou de fundos específicos para tanto.

Isto posto, retomamos o contraste das visões de Hans Jonas e de Cass Sunstein, que mencionamos no início deste trabalho, para concluir que é preciso gerir os riscos em uma dimensão ética, de um princípio responsabilidade para o futuro. No entanto, não precisamos tecer a profecia da desgraça: o ser humano é capaz de desenvolver ações de prevenção, precaução e resiliência para a preservação e adaptação do meio ambiente e do meio social diante dos riscos de desastres, visando ao equilíbrio socioambiental. O direito não é capaz de fazê-lo sozinho, mas traz interessantes ferramentas de indução de comportamentos desejáveis. Para alcançar esse seu objetivo, o diálogo entre as diferentes ciências que lidam com riscos ambientais é salutar. 


\section{REFERÊNCIAS}

AGÊNCIA ESTADO. Mineradora assina termo de ajustamento de conduta. Estadão, de 07 mar. 2006. Disponível em: <http://www.estadao.com.br/noticias/geral,mineradora-assinatermo-de-ajustamento-de-conduta,20060307p62031>. Acesso em: 02 dez. 2016.

ALVIM, Agostinho. Da inexecução das obrigações e suas consequências. 5. ed. São Paulo: Saraiva, 1980.

AMARAL, Ana Carolina. Acordo de Paris entra em vigor em tempo recorde. Folha de S.Paulo, de 05 nov. 2016, Ambiente. Disponível em:

$<$ http://www1.folha.uol.com.br/ambiente/2016/11/1829605-acordo-de-paris-entra-emvigor-em-tempo-recorde.shtml>Acesso em: 07 nov. 2016.

ANTUNES, Paulo Bessa. Direito ambiental. 14. ed. São Paulo: Atlas, 2012.

ANTUNES, Tiago. Os desastres naturais e as alterações climáticas: em especial a resposta do ordenamento jurídico aos fenómenos meteorológicos extremos. In: GOMES, Carla Amado (Coord.). Direito(s) das catástrofes naturais. Coimbra: Almedina, 2012. cap. 2, p. 71-140.

ARAGÃO, Maria Alexandra de Sousa. Prevenção de riscos na União Europeia: o dever de tomar em consideração a vulnerabilidade social para uma protecção civil eficaz e justa.

Revista Crítica de Ciências Sociais, Coimbra, Centro de Estudos Sociais (CES), Universidade de Coimbra, n. 93, p. 71-93, 2011. [Online, p. 1-24]. Disponível em: $<$ http://rccs.revues.org/174>. Acesso em: 02 nov. 2016.

ARAGÃO, Maria Alexandra de Sousa. O princípio do nível elevado de protecção e a renovação ecológica do direito do ambiente e dos resíduos. Coimbra: Almedina, 2006.

ARAGÃO, Maria Alexandra de Sousa. O princípio do poluidor pagador: pedra angular da política comunitária do ambiente. Coimbra: Coimbra Editora, 1997.

ARAGÃO, Maria Alexandra de Sousa. Princípio da precaução: manual de instruções. Revista do Centro de Estudos de Direito do Ordenamento, do Urbanismo e do Ambiente, Coimbra, Faculdade de Direito da Universidade de Coimbra, v. 11, n. 22, p. 9-58, 2008.

ARAÚJO, Heriberto. A dor de ver um povoado desaparecer. El País, Brasil, de 09 nov. 2015. Disponível em:

$<$ http://brasil.elpais.com/brasil/2015/11/09/politica/1447080717_613195.html>. Acesso em: 10 out. 2016.

ARAÚJO, Heriberto. Tsunami de lama tóxica, o maior desastre ambiental do Brasil. $E l$ País, Brasil, de 31 dez. 2015. Disponível em:

$<$ http://brasil.elpais.com/brasil/2015/12/30/politica/1451479172_309602.html>. Acesso em: 10 out. 2016. 
ARCHER, António Barreto. Direito do ambiente e responsabilidade civil. Coimbra: Almedina, 2009.

ARNOLD, Craig Anthony; GUNDERSON, Lance H. Adaptive Law and resilience. Environmental Law Reporter, v. 43, p. 10.426-10.443, May 2013. Disponível em: $<$ http://ssrn.com/abstract=2225619>. Acesso em: 20 out. 2016.

ASIAN DEVELOPMENT BANK. Investing in resilience: ensuring a disaster-resistant future. Mandaluyong City, Philippines: Asian Development Bank, 2013. Disponível em: $<$ https://www.adb.org/sites/default/files/publication/30119/investingresilience.pdf $>$.Acesso em: 02 nov. 2016.

AZEVEDO, Antonio Junqueira de. Por uma nova categoria de dano na responsabilidade civil: o dano social. In: FILOMENO, José Geraldo Brito; WAGNER JUNIOR, Luiz Guilherme da Costa; GONÇALVES, Renato Afonso (Coords.). O Código Civil e a sua interdisciplinaridade: reflexos do Código Civil nos demais ramos do direito. Belo Horizonte: Del Rey, 2004. p. 370-377.

BECK, Ulrich. La sociedad del riesgo global. Traducción de Jesus Albores Rey. Madrid: Siglo XXI de España Traductores, 2002.

BENJAMIN, Antônio Herman Vasconcellos e. Responsabilidade civil pelo dano ambiental. Revista de Direito Ambiental, São Paulo, v. 3, n. 9, p. 5-52, jan./mar. 1998. Disponível em:

$<$ http://bdjur.stj.jus.br/jspui/bitstream/2011/44994/responsabilidade_civil_dano_ambiental _benjamin.pdf $>$. Acesso em: 10 out. 2016.

BERTONI, Estêvão; MARQUES, José. Sem funcionários, barragem que ruiu ficou 10 dias sem monitoramento. Folha de S.Paulo, de 12 maio 2016, B1, Caderno Cotidiano.

Disponível em: <http://www1.folha.uol.com.br/cotidiano/2016/05/1770367-barragem-queruiu-em-mariana-mg-ficou-10-dias-sem-monitoramento.shtml $>$. Acesso em: 10 out. 2016.

BIANCA, C. Massimo. Diritto civile: la responsabilità. Reimpr. Milano: A. Giuffrè, 2004. v. 5.

BILLET, Philippe. Le droit communautaire face aux catastrophes naturelles: la construction d'un droit de la solidarité. In: LAVIEILLE, Jean-Marc; BÉTAILLE, Julien; PRIEUR, Michel (Dirs.). Les catastrophes écologiques et le droit: échecs du droit, appels au droit. [Actes du Colloque International de Limoges des 11,12 et 13 mars 2009, organisé par CRIDEAU-OMIJ et CIDCE]. Bruxelles: Bruylant, 2012. Chapitre 3, Section 5, p. 131153.

BOUTONNET, Mathilde. L'influence du principe de précaution sur la responsabilité civile en droit français: un bilan en demi-teinte. McGill International Journal of Sustainable Development Law and Policy (JSDLP), Montreal, Canada, v. 10, No. 1, p. 105-136, Fall 2014. [JSDLP Online, p. 8-38]. Disponível em: $<$ https://www.mcgill.ca/jsdlp/files/jsdlp/boutonnet_10-1.pdf $>$. Acesso em: 01 set. 2016. 
BRASIL. Departamento Nacional de Produção Mineral (DNPM). Cadastro Nacional de Barragens de Mineração. Disponível em:

$<$ http://www.dnpm.gov.br/assuntos/barragens/cadastro-nacional-de-barragens-demineracao>. Acesso em: 10 nov. 2016.

BRASIL. Ministério da Integração Nacional. Reconhecimentos realizados em 2016. Disponível em: $<$ http://www.mi.gov.br/reconhecimentos-realizados $>$. Acesso em: $02 \mathrm{dez}$. 2016.

BRASIL. Procuradoria Geral da República (PGR). MPF/Itaperuna aciona mineradora por acidente no noroeste fluminense. Notícias, 08 mar. 2006. Disponível em:

$<$ http://www.mpf.mp.br/pgr/noticias-pgr/mpf-itaperuna-aciona-mineradora-por-acidenteno-noroeste-fluminense-20060308>. Acesso em: 20 set. 2016.

BUCCI, Maria Paula Dallari. Fundamentos de uma teoria jurídica das políticas públicas. São Paulo: Saraiva, 2013.

BUCCI, Maria Paula Dallari. Notas para uma metodologia jurídica de análise de políticas públicas. In: FORTINI, Cristiana; ESTEVES, Júlio Cesar Santos; DIAS, Maria Tereza Fonseca (Orgs.). Políticas públicas: possibilidades e limites. Belo Horizonte: Fórum, 2008. p. $225-260$.

BUSTAMANTE, Thomas da Rosa de; SILVA, Denis Franco. Neminem laedere: o novo Código Civil Brasileiro e a integral reparabilidade dos danos materiais decorrentes de ato ilícito. Revista Trimestral de Direito Civil: RTDC, Rio de Janeiro, Padma, v. 5, n. 20, p. 247-258, out./dez. 2004.

CAHALI, Yussef Said. Responsabilidade civil do Estado. 4. ed. São Paulo: Revista dos Tribunais, 2013.

CARRINGTON, Damian. Climate change threatens ability of insurers to manage risk. The Guardian, Climate Change, 7 December 2016. Disponível em:

$<$ https://www.theguardian.com/environment/2016/dec/07/climate-change-threatens-abilityinsurers-manage-risk?CMP=twt_a-environment_b-gdneco>. Acesso em: 10 dez. 2016.

CARTA Encíclica 'Laudato Si’ do Santo Padre Francisco sobre o Cuidado da Casa Comum. Disponível em:

$<$ http://w2.vatican.va/content/francesco/pt/encyclicals/documents/papafrancesco_20150524_enciclica-laudato-si.html>. Acesso em: 10 out. 2016.

CARVALHO, Délton Winter de. Dano ambiental futuro: a responsabilização civil pelo risco ambiental. 2. ed. rev., atual. e ampl. Porto Alegre: Livraria do Advogado, 2013.

CARVALHO, Délton Winter de. O papel do direito e os instrumentos de governança ambiental para prevenção dos desastres. Revista de Direito Ambiental, São Paulo, Revista dos Tribunais, v. 19, n. 75, p. 45-74, jul./set. 2014. [online, p. 1-23].

CARVALHO, Délton Winter de; DAMACENA, Fernanda Dalla Libera. Direito dos desastres. Porto Alegre: Livraria do Advogado, 2013. 
CARVALHO, Délton Winter de; DAMACENA, Fernanda Dalla Libera. A intensificação dos desastres naturais, as mudanças climáticas e o papel do direito ambiental. Revista de Informação Legislativa, Brasília, DF, v. 49, n. 193, p. 83-97, jan./mar. 2012.

CARVALHO, Délton Winter de; DAMACENA, Fernanda Dalla Libera. O seguro como instrumento de adaptação às mudanças climáticas e redução de riscos de desastres ambientais. Revista de Direito Ambiental, São Paulo, Revista dos Tribunais, v. 20, n. 80, p. 451-474, nov./dez. 2015. [Online].

CAVALIERI FILHO, Sérgio. Programa de responsabilidade civil. 12. ed. rev. e ampl. São Paulo: Atlas, 2015.

CENTRE FOR RESEARCH ON THE EPIDEMIOLOGY OF DISASTERS (CRED). EM-DAT. Disponível em: <http://www.emdat.be/>. Acesso em: 16 set. 2016.

CENTRO DE TECNOLOGIA MINERAL (CETEM). Rompimento de barragem da Mineradora Rio Pomba Cataguases afeta qualidade da água em MG e no RJ. 18 jul. 2012. Disponível em: <http://www.cetem.gov.br/images/palestras/2015/mariana/verbete-riopomba.pdf $>$. Acesso em: 20 set. 2016.

COLETTE, April. L. The politics of framing risk: minding the vulnerability gap in climate change research. World Development Perspectives, v. 1, p. 43-48, Mar. 2016. Disponível em: <http://www.sciencedirect.com/science/article/pii/S2452292916300686>. Acesso em: 20 out. 2016.

COSTA, Karen. Analysis of legislation related do disaster risk reduction in Brazil.

Geneva: International Federation of Red Cross and Red Crescent Societies (IFRC), 2012. Disponível em: $<$ https://www.ifrc.org/PageFiles/93556/1213800-IDRL_Analysis_BrazilEN-LR.pdf $>$. Acesso em: 10 out. 2016.

CRUZ, Gisela Sampaio da. O problema do nexo causal na responsabilidade civil. Rio de Janeiro: Renovar, 2005.

CUSTÓDIO, Helita Barreira. Responsabilidade civil por danos ao meio ambiente. Campinas: Millennium, 2006.

CUTTER, Susan L. The science of vulnerability and the vulnerability of science. In:

CUTTER, Susan L. Hazards, vulnerability and environmental justice. London: Earthscan, 2006. cap. 9, p. 133-148.

CUTTER, Susan L. Vulnerability to environmental hazards. In: CUTTER, Susan L. Hazards, vulnerability and environmental justice. London: Earthscan, 2006. cap. 6, p. 71 71-82.

DELLINGER, Myanna F. Rethinking "fuerza mayor" in a world of anthropogenic climate change. Derecho \& Sociedad, Lima, Pontificia Universidad Católica del Perú (PUCP), n. 42, p. 45-59, 2014. [Online]. Disponível em:

$<$ http://revistas.pucp.edu.pe/index.php/derechoysociedad/article/view/12466/13026>. Acesso em: 20 ago. 2016. 
DEMANGE, Lia Helena Monteiro de Lima. The principle of resilience. Pace Environmental Law Review, New York, v. 30, n. 2, p. 695-810, Spring 2013. Disponível em: $<$ http://digitalcommons.pace.edu/cgi/viewcontent.cgi?article=1726\&context=pelr $>$. Acesso em: 02 nov. 2016.

DESASTRE em Mariana é o maior acidente mundial com barragens. Terra, 15 jan. 2016. Disponível em: $<$ https://noticias.terra.com.br/brasil/desastre-em-mariana-e-o-maioracidente-mundial-com-barragens-em-100anos, 874a54e18a812fb7cab2d7532e9c4b72ndnwm3fp.html>. Acesso em: 10 out. 2016.

DIAS, José de Aguiar. Da responsabilidade civil. 10. ed., 2. tir. rev. e aum. Rio de Janeiro: Forense, 1995. v. 2.

DIREITO, Carlos Alberto Menezes; CAVALIERI FILHO, Sérgio. Comentários ao novo Código Civil: da responsabilidade civil: das preferências e privilégios creditórios: arts. 927 a 965. Coordenação de Sálvio de Figueiredo Teixeira. Rio de Janeiro: Forense, 2004. v. 13.

DUGUIT, Léon. Las transformaciones del derecho público y privado. Traducción de Adolfo G. Posada, Ramon Jaen y Carlos G. Posada. Buenos Aires: Heliasta, 1975.

DUPUY, Jean-Pierre. Ainda há catástrofes naturais? Análise Social, Lisboa, v. 41, n. 181, p. 1.181-1.193, 2006. Disponível em:

<http://www.scielo.mec.pt/pdf/aso/n181/n181a12.pdf>. Acesso em: 20 nov. 2016.

EAGLE, Joel. Divine intervention: re-examining the act of God defense in a post-Katrina world. Chicago-Kent Law Review, v. 82, p. 459-493, 2007. [Online]. Disponível em: $<$ http://scholarship.kentlaw.iit.edu/cklawreview/vol82/iss1/15> Acesso em: 10 set. 2016.

EWALD, François. The return of Descarte's malicious demon: an outline of a philosophy of precaution. Translated by Stephen Utz. In: BAKER, Tom; SIMON, Jonathan (Eds.). Embracing risk: the changing culture of insurance and responsibility. Chicago: University of Chicago Press, 2002. cap. 11, p. 273-301.

FACKLER, Martin. Tsunami warnings, written in stone. The New York Times, 20 April 2011. Disponível em: <http://www.nytimes.com/2011/04/21/world/asia/21 stones.html $>$. Acesso em: 02 nov. 2016.

FARBER, Daniel A. Disaster law and emerging issues in Brazil = Direito dos desastres e questões emergentes no Brasil. Revista de Estudos Constitucionais, Hermenêutica e Teoria do Direito (RECHTD), São Leopoldo, RS, v. 4, n. 1, p. 4-5, jan./jun. 2012. Disponível em: $<$ http://revistas.unisinos.br/index.php/RECHTD/article/view/rechtd.2012.41.01/932>. Acesso em: 10 out. 2016.

FARBER, Daniel A. Introduction: legal scholarship, the disaster cycle, and the Fukushima accident. Duke Environmental Law \& Policy Forum, Durham, NC, v. 23, No. 1, p. 1-21, Fall 2012. Disponível em: <http://scholarship.law.duke.edu/delpf/vol23/iss1/1>. Acesso em: 02 nov. 2016. 
FARBER, Daniel A. Navigating the intersection of environmental law and disaster law. BYU Law Review, v. 2011, issue 6, article 1, p. 1.783-1.820, 2011. Disponível em: $<$ http://digitalcommons.law.byu.edu/cgi/viewcontent.cgi?article=2622\&context=lawrevie w>. Acesso em: 10 out. 2016.

FARBER, Daniel A. Tort law in the era of climate change, Katrina, and 9/11: exploring liability for extraordinary risks. Valparaiso University Law Review, Valparaiso, v. 43, n. 3, p. 1.075-1.130, 2008-2009. Disponível em:<scholarship.law.berkeley.edu/facpubs/995/>. Acesso em: 18 jul. 2016.

FARBER, Daniel A. Uncertainty. Georgetown Law Journal, Berkeley, CA, v. 99, p. 901959, 2011. UC Berkeley Public Law Research Paper No. 1555343. Disponível em: $<$ https://ssrn.com/abstract=1555343>. Acesso em: 20 out. 2016.

FARBER, Daniel A. et al. Disaster law and policy. 3rd ed. New York: Wolters Kluwer, 2015.

FARIAS, Cristiano Chaves de; BRAGA NETTO, Felipe Peixoto; ROSENVALD, Nelson. Novo tratado de responsabilidade civil. São Paulo: Atlas, 2015.

FENSTERSEIFER, Tiago. A responsabilidade do Estado pelos danos causados às pessoas atingidas pelos desastres ambientais ocasionados pelas mudanças climáticas: uma análise à luz dos deveres de proteção ambiental do Estado e da correspondente proibição de insuficiência na tutela do direito fundamental ao ambiente. In: LAVRATTI, Paula; PRESTES, Vanêsca Buzelato (Orgs.). Direito e mudanças climáticas: responsabilidade civil e mudanças climáticas. São Paulo: Instituto O Direito por um Planeta Verde, 2010. p. 79-107. (Direito e Mudanças Climáticas, v. 2). Disponível em:

$<$ http://www.planetaverde.org/arquivos/biblioteca/arquivo_20131201175520_2338.pdf>. Acesso em: 20 out. 2016.

FERNÁNDEZ CABANAS, Juan José. El resarcimiento de los daños causados por catástrofes naturales. Granada: Comares, 2015.

FRANÇA, Rubens Limongi. Instituições de direito civil. São Paulo: Saraiva, 1988.

FUNDÃO TAILINGS DAM REVIEW PANEL. Report on the immediate causes of the failure of the Fundão Dam. 25 Aug. 2016. By Norbert R. Morgenstern (Chair); Steven G. Vick; Cássio B. Viotti; Bryan D. Watts. Disponível em: $<$ http://fundaoinvestigation.com $>$. Acesso em: 10 out. 2016.

GAILLARD, Émilie. Générations futures et droit privé: vers un droit des générations futures. Paris: LGDJ-Lextenso éd., 2011. (Bibliothèque de Droit Prive, v. 527).

GARCIA, Maria da Glória F. P. D. Princípio da precaução: lei do medo ou razão de esperança? In: CORREIA, Fernando Alves; MACHADO, Jónatas Eduardo Mendes; LOUREIRO, João Carlos Simões Gonçalves (Orgs.). Estudos em homenagem ao prof. doutor José Gomes Canotilho: responsabilidade entre passado e futuro. Coimbra: Coimbra Editora, 2012. v. 1, p. 315-330. 
GARMESTANI, Ahjond S.; ALLEN, Craig R.; BENSON, Melinda H. Can law foster social-ecological resilience? Ecology and Society, v. 18, No. 2, art. 37, 2013 [online]. Disponível em: <http://www.ecologyandsociety.org/vol18/iss2/art37/>. Acesso em: 02 nov. 2016.

GODOY, Cláudio Luiz Bueno de. Responsabilidade civil pelo risco da atividade: uma cláusula geral no Código Civil de 2002. 2. ed. São Paulo: Saraiva, 2010.

GOMES, Carla Amado. Catástrofes naturais e acidentes industriais graves na União Europeia: a prevenção à prova nas directivas Seveso. O Direito, Lisboa, Almedina, ano 143, n. 3, p. 459-488, 2011.

GOMES, Orlando. Direitos reais. 19. ed. atualizada e aumentada por Luiz Edson Fachin. Rio de Janeiro: Forense, 2008.

GOMIS CATALÁ, Lucía. Responsabilidad por daños al medio ambiente. Pamplona: Aranzadi, 1998.

GONÇALVES, Carlos Roberto. Comentários ao Código Civil: do direito das obrigações: arts. 927 a 965. Coordenação de Antonio Junqueira de Azevedo. São Paulo: Saraiva, 2003. v. 11 .

GONÇALVES, Carlos Roberto. Direito civil brasileiro: responsabilidade civil. 10. ed. São Paulo: Saraiva, 2015. v. 4.

GRAU, Eros Roberto. Solo criado. Revista de Direito Imobiliário, São Paulo, Revista dos Tribunais, v. 24, n. 51, p. 20-45, jul./dez. 2001.

GUÉGAN, Anne. L'apport du principe de précaution au droit de la responsabilité civile. Revue Juridique de L'Environnement, Limoges, v. 25, n. 2, p. 147-178, 2000.

HOLLING, C. S. Response to "Panarchy and the Law". Ecology and Society, v. 17, No. 4, art. 37, 2012. Disponível em: <http://www.ecologyandsociety.org/vol17/iss4/art37/>. Acesso em: 02 nov. 2016.

INSTITUTO BRASILEIRO DO MEIO AMBIENTE E DOS RECURSOS NATURAIS RENOVÁVEIS (IBAMA). Laudo técnico preliminar: impactos ambientais decorrentes do desastre envolvendo o rompimento da barragem de Fundão, em Mariana, Minas Gerais. Brasília, nov. de 2015. Disponível em:

$<$ http://www.ibama.gov.br/phocadownload/noticias/noticias2016/laudo_tecnico_preliminar _Ibama.pdf $>$. Acesso em: 28 dez. 2016.

INSTITUTO DE PESQUISAS TECNOLÓGICAS DO ESTADO DE SÃO PAULO (IPT). Rejeitos de mineração: tratamento de rejeitos é solução alternativa e economicamente viável à barragem de mineradoras. Notícias, de 16.02.2016. Disponível em: $<$ http://www.ipt.br/noticia/1043.htm>. Acesso em: 10 nov. 2016. 
INTERNATIONAL FEDERATION OF RED CROSS AND RED CRESCENT

SOCIETIES (IFRC). IFRC Strategic Framework on Gender and Diversity Issues 20132020. Geneva, 2013. Disponível em:

$<$ http://www.ifrc.org/Global/Documents/Secretariat/201412/IFRC\%20Strategic\%20Frame work $\% 20$ on $\% 20$ Gender\%20and\%20Diversity\%20Issues-English.pdf $>$. Acesso em: 10 nov. 2016.

JONAS, Hans. O princípio responsabilidade: ensaio de uma ética para a civilização tecnológica. Tradução de Marijane Lisboa e Luiz Barros Montez. Rio de Janeiro: Contraponto; Ed. PUC-Rio, 2006.

JORNADAS DE DIREITO CIVIL I, III, IV e V: enunciados aprovados. Coordenador científico Ministro Ruy Rosado de Aguiar Júnior. Brasília, DF: Conselho da Justiça Federal (CJF), Centro de Estudos Judiciários, 2012. Disponível em:

$<$ http://www.cjf.jus.br/cjf/corregedoria-da-justica-federal/centro-de-estudos-judiciarios1/publicacoes-1/jornadas-cej/EnunciadosAprovados-Jornadas-1345.pdf >. Acesso em: 23 dez. 2016.

KEHOE, John. BHP Billiton partner Vale sued by US investors for Brazil Samarco dam disaster. The Australian Financial Review Magazine, ARF Weekend, 09 dez. 2015. Disponível em: $<$ http://www.afr.com/business/mining/bhp-partner-vale-sued-by-usinvestors-for-brazilian-samarco-dam-disaster-20151208-glityh>. Acesso em: 10 out. 2016.

KONDER, Carlos Nelson. A redução equitativa da indenização em virtude do grau de culpa: apontamentos acerca do parágrafo único do art. 944 do Código Civil. Revista Trimestral de Direito Civil: RTDC, Rio de Janeiro, Padma, v. 8, n. 29, p. 3-34, jan./mar. 2007.

KOURILSKY, Philippe; VINEY, Geneviève. Le principe de précaution. Rapport au Premier Ministre. 15 oct. 1999. Disponível em:

$<$ http://www.ladocumentationfrancaise.fr/var/storage/rapports-publics/004000402.pdf $>$. Acesso em: 20 nov. 2016.

LAVIEILLE, Jean Marc; BÉTAILLE, Julien; PRIEUR, Michel (Dirs.). Les catastrophes écologiques et le droit: échecs du droit, appels au droit. Bruxelles, Bruylant, 2012.

LEITE, José Rubens Morato; AYALA, Patryck de Araújo. Dano ambiental: do individual ao coletivo extrapatrimonial: teoria e prática. 4. ed. rev., atual. e ampl. São Paulo: Revista dos Tribunais, 2011.

LEMOS, Patrícia Faga Iglecias. Meio ambiente e responsabilidade civil do proprietário: análise do nexo causal. 2. ed., rev., atual. e ampl. em 2012, de acordo com o Novo Código Florestal (Lei 12.651/2012) e a MP 571/2012. São Paulo: Revista dos Tribunais, 2012.

LEMOS, Patrícia Faga Iglecias. Resíduos sólidos e responsabilidade civil pós-consumo. 3. ed. rev. e atual. São Paulo: Revista dos Tribunais, 2014.

LIMA, Alvino. Culpa e risco. 2. ed., 2. tir., rev. e atual. pelo Prof. Ovidio Rocha Barros Sandoval. São Paulo, Revista dos Tribunais, 1999. 
LINDBLOM, Charles E. Muddling through 2: a ubiquidade da decisão incremental. In: HEIDEMANN, Francisco G.; SALM, José Francisco (Orgs.). Políticas públicas e desenvolvimento: bases epistemológicas e modelos de análise. 2. ed. Brasília: Editora Universidade de Brasília, 2010. p. 181-202.

LÔBO, Paulo Luiz Neto. Direito civil: parte geral. 4. ed. São Paulo: Saraiva, 2013.

LOPEZ, Teresa Ancona. Princípio da precaução e evolução da responsabilidade civil. São Paulo: Quartier Latin, 2010.

LORENZETTI, Ricardo Luis. Fundamentos do direito privado. Tradução de Vera Maria Jacob de Fradera. São Paulo: Revista dos Tribunais, 1998.

MANYENA, Siambabala Bernard. The concept of resilience revisited. Disasters, v. 30, No. 4, p. 433-450, Dec. 2006. Disponível em:

$<$ http://onlinelibrary.wiley.com/doi/10.1111/j.0361-3666.2006.00331.x/pdf $>$. Acesso em: 09 set. 2016.

MAZEAUD, Henri; MAZEAUD, Léon. Traité theorique et pratique de la responsabilité civile: délictuelle et contractuelle. 4. ed. Paris: Librairie du Recueil Sirey, 1950. v. 3.

McENTIRE, David. Triggering agents, vulnerabilities and disaster reduction: towards a holistic paradigm. Disaster Prevention and Management, v. 10, No. 3, p. 189-196, 2001.

McENTIRE, David; MPH, Colleen Gilmore Crocker; PETERS, Ekong. Addressing vulnerability through an integrated approach. International Journal of Disaster Resilience in the Built Environment, v. 1, No. 1, p. 50-64, Feb. 2010.

McEVOY, Arthur F. The role of law in engineering "natural" disasters. Oñati Socio-Legal Series [online], v. 3, No. 2, p. 293-311, 2013. Disponível em:

$<$ http://opo.iisj.net/index.php/osls/article/view/188/199>. Acesso em: 17 ago. 2016.

MENDES, João Múcio Amado et al. Waste management and disaster prevention in Brazilian law: a necessary dialogue towards urban resilience. In: CRETE $2014-$ INTERNATIONAL CONFERENCE IN INDUSTRIAL AND HAZARDOUS WASTE MANAGEMENT, 4. 2014, Chania, Crete, Greece: Technical University of Crete, 2014. p. 301-302.

MENDONÇA, Diogo Naves. Análise econômica da responsabilidade civil: o dano e sua quantificação. São Paulo: Atlas, 2012.

MILARÉ, Édis. Direito do ambiente. 10. ed. rev., atual. e ampl. São Paulo: Revista dos Tribunais, 2015.

MIRANDA, Pontes de. Tratado de direito privado: parte especial: direito das obrigações: consequências do inadimplemento: exceções de contrato não adimplido, ou adimplido insatisfatoriamente, e de inseguridade: enriquecimento injustificado: estipulação a favor de terceiro: eficácia protectiva de terceiro: mudanças de circunstâncias: compromisso.

Atualizado por Ruy Rosado de Aguiar Júnior e Nelson Nery Junior. São Paulo: Revista dos Tribunais, 2012. v. 26. 
MIRANDA, Pontes de. Tratado de direito privado: parte especial: direito das obrigações: fatos ilícitos absolutos: responsabilidade: danos causados por animais: coisas inanimadas e danos: Estado e servidores: profissionais. Atualizado por Rui Stoco. São Paulo: Revista dos Tribunais, 2012. v. 53.

MORAES, Maria Celina Bodin de. Punitive damages em sistemas civilistas: problemas e perspectivas. Revista Trimestral de Direito Civil: RTDC, Rio de Janeiro, Padma, v. 5, n. 18, p. 45-78, abr.jun. 2004.

MORSELLO, Marco Fábio. A responsabilidade civil e a socialização dos riscos: o sistema neozelandês e a experiência escandinava. Revista da Escola Paulista da Magistratura, São Paulo, v. 7, n. 2, p. 13-22, jul./dez. 2006.

MOSSET ITURRASPE, Jorge. Responsabilidad por daños: parte general. Reimpr. Buenos Aires: Rubinzal-Culzoni, 2004. v. 1.

NABAIS, José Cabalta. Por uma liberdade com responsabilidade: estudos sobre direitos e deveres fundamentais. Coimbra: Coimbra Editora, 2007.

NEVES, António Castanheira. O direito interrogado pelo tempo presente na perspectiva do futuro. Boletim da Faculdade de Direito, Coimbra, Universidade de Coimbra, n. 83, p. 173, 2007.

O'BRIEN, Geoff et al. Climate change and disaster management. Disasters, v. 30, No. 1, p. 64-80, Apr. 2006. Disponível em: <http://onlinelibrary.wiley.com/doi/10.1111/j.14679523.2006.00307.x/epdf>. Acesso em: 20 jun. 2016.

O'KEFEE, Phil; WESTGATE, Ken; WISNER, Bem. Taking the naturalness out of natural disasters. Nature, v. 260, p. 566-567, Apr. 151976.

OLIVEIRA, Ana Perestrelo de. Causalidade e imputação na responsabilidade civil ambiental. Coimbra: Almedina, 2007.

OLIVEIRA, Fernanda Paula; LOPES, Dulce. Catástrofes naturais e direito do urbanismo. In: GOMES, Carla Amado (Coord.). Direito(s) das catástrofes naturais. Coimbra: Almedina, 2012. cap. 4, p. 173-207.

ONU critica Brasil, Vale e BHP por resposta 'inaceitável' a desastre de Mariana. $B B C$ Brasil, 25 nov. 2015. Disponível em:

$<$ http://www.bbc.com/portuguese/noticias/2015/11/151125_onu_brasil_mariana_fd $>$. Acesso em: 10 out. 2016.

OSAKA, Eri. Corporate liability, government liability, and the Fukushima nuclear disaster. Pacific Rim Law \& Policy Journal, v. 21, n. 3, p. 451-458, jun. 2012. Disponível em: $<$ https://digital.law.washington.edu/dspacelaw/bitstream/handle/1773.1/1161/21PRPLJ433.pdf?sequence=1>. Acesso em: 08 jul. 2016). 
PALLIYAGURU, Roshani; AMARATUNGA, Dilanthi; BALDRY, David. Constructing a holistic approach to disaster risk reduction: the significance of focusing on vulnerability reduction. Disasters, v. 38, No. 1, p. 45-61, Jan. 2014. Disponível em:

$<$ http://eprints.hud.ac.uk/23049/1/item\%2046.pdf>. Acesso em: 20 set. 2016.

PEREIRA, Caio Mário da Silva. Instituições de direito civil: teoria geral das obrigações. 20. ed. rev. e atual. por Luiz Roldão de Freitas Gomes. Rio de Janeiro: Forense, 2004. v. 2.

PERLINGIERI, Pietro. Perfis do direito civil: introdução ao direito civil constitucional. Tradução de Maria Cristina de Cicco. 2. ed. Rio de Janeiro: Renovar, 2002.

PIDOT, Justin. Deconstructing disaster. Brigham Young University Law Review, No. 2, article 1, p. 213-257, 2013. Disponível em:

$<$ http://digitalcommons.law.byu.edu/cgi/viewcontent.cgi?article=2707\&context=lawrevie w>. Acesso em: 02 nov. 2016.

PINTO, Victor Carvalho. Direito urbanístico: plano diretor e direito de propriedade. São Paulo: Revista dos Tribunais, 2005.

POLÍTICA, ECONOMIA, MINERAÇÃO, AMBIENTE E SOCIEDADE (PoEMAS). Antes fosse mais leve a carga: avaliação dos aspectos econômicos, políticos e sociais do desastre da Samarco/Vale/BHP em Mariana (MG): relatório final. Mimeo. 2015.

Disponível em: < http://www.ufjf.br/poemas/files/2014/07/PoEMAS-2015-Antes-fossemais-leve-a-carga-versão-final.pdf $>$. Acesso em: 10 out. 2016.

PRIEUR, Michel. Droit de l'environnement. 4. ed. Paris: Dalloz, 2001.

PÜSCHEL, Flavia Portella. Funções e princípios justificadores da responsabilidade civil e o art. 927, § único do Código Civil. Revista Direito GV, São Paulo, Fundação Getulio Vargas, v. 1, n. 1, p. 91-107, maio 2005.

REALE, Miguel. Visão geral do novo Código Civil. Revista Jus Navigandi, Teresina, ano 7, n. 54, 1 fev. 2002. Disponível em: <https://jus.com.br/artigos/2718>. Acesso em: 08 jan. 2017.

REGO, Margarida Lima; SILVA, Rute Carvalho da. Os seguros de riscos catastróficos. In: GOMES, Carla Amado (Coord.). Direito(s) das catástrofes naturais. Coimbra: Almedina, 2012. cap. 6, p. 269-322.

REJDA, George E. Principles of risk management and insurance. 9th ed. Boston, MA: Addison Wesley, 2005.

REJEITOS da mineração. Pesquisa Fapesp, n. 240, p. 14, fev. 2016. [Online]. Disponível em: $<$ http://revistapesquisa.fapesp.br/2016/02/19/rejeitos-da-mineracao/>. Acesso em: 10 nov. 2016.

RENN, Ortwin. Risk governance: coping with uncertainty in a complex world. London; Sterling, VA: Earthscan, 2008. 
RIPLEY, Randall B. Stages of the policy process. In: MCCOOL, Daniel C. Public policy: theories, models and concepts: an anthology. New Jersey: Prentice Hall, 1995. p. 158-161.

ROBINSON, Nicholas A. Fundamental principles of law for the anthropocene?

Environmental Policy \& Law, v. 44, No. 1-2, p. 13-27, 2014. Disponível em:

$<$ http://digitalcommons.pace.edu/lawfaculty/964/>. Acesso em: 02 nov. 2016.

ROBINSON, Nicholas A. The resilience principle. IUCN Academy of Environmental Law eJournal, n. 19, p. 18-27, 2014. Disponível em:

$<$ http://digitalcommons.pace.edu/cgi/viewcontent.cgi?article=1951\&context=lawfaculty $>$. Acesso em: 02 nov. 2016.

ROSENVALD, Nelson. As funções da responsabilidade civil: a reparação e a pena civil. 2. ed. São Paulo: Atlas, 2014.

RUHL, J. B. General design principles for resilience and adaptive capacity in legal systems: with applications to climate change adaption. North Carolina Law Review, v. 89, No. 5, p. 1.375-1404, 2011. Disponível em:

$<\mathrm{http}$ ://scholarship.law.unc.edu/cgi/viewcontent.cgi?article $=4506 \&$ context $=\mathrm{ncl}>$. . Acesso em: 20 jun. 2016.

RUHL, J. B. Panarchy and the law. Ecology and Society, v. 17, No. 3, art. 31, 2012.

Disponível em: <http://dx.doi.org/10.5751/ES-05109-170331>. Acesso em: 02 nov. 2016.

SANSEVERINO, Paulo de Tarso Vieira. Princípio da reparação integral: indenização no Código Civil. 2. tiragem. São Paulo: Saraiva, 2010.

SARAIVA, Rute. A abordagem comportamental do direito e da economia das catástrofes naturais. In: INSTITUTO DE CIÊNCIAS JURIDICO-POLÍTICAS (ICJP). Actas do Colóquio Catástrofes Naturais: uma realidade multidimensional. Faculdade de Direito da Universidade de Lisboa, 24 out. 2012. Lisboa: ICJP, 2013. p. 95-108. Disponível em: $<$ http://www.icjp.pt/sites/default/files/publicacoes/files/ebook_catastrofes_final1_isbn.pdf >. Acesso em: 02 nov. 2016.

SCHREIBER, Anderson. Novos paradigmas da responsabilidade civil: da erosão dos filtros da reparação à diluição dos danos. 5. ed. São Paulo: Atlas, 2013.

SENDIM, José de Sousa Cunhal. Responsabilidade civil por danos ecológicos: da reparação do dano através de restauração natural. Coimbra: Coimbra Editora, 1998.

SÉGUR, Philippe. Le catastrophe et le risque naturels: essai de définition juridique. Revue du Droit Public et de la Science Politique en France et a l'Étranger, Paris, Librairie Générale de Droit et de Jurisprudence, n. 6, p. 1.693-1.716, nov./déc. 1997.

SILVA, José Afonso da. Direito ambiental constitucional. São Paulo: Malheiros, 1994.

SILVA, José Afonso da. Direito urbanístico brasileiro. 4. ed. rev. e atual. São Paulo: Malheiros, 2006. 
STEICHEN, Pascale. La responsabilité environnementale et les catastrophes. In: LAVIEILLE, Jean-Marc (Dir.); BÉTAILLE, Julien; PRIEUR, Michel. Les catastrophes écologiques et le droit: échecs du droit, appels au droit. Bruxelles: Bruylant, 2012. Chapitre 8, Section 1, p. 421-452.

SUNSTEIN, Cass R. Laws of fear: beyond the precautionary principle. Cambridge, UK; New York: Cambridge University Press, 2005.

SUNSTEIN, Cass R. Risk and reason: safety, law and the environment. Cambridge, UK; New York: Cambridge University Press, 2002.

TAPINOS, Daphné. Prévention, précaution et responsabilité civile: risque avéré, risque suspecté et transformation du paradigme de la responsabilité civile. Paris: L'Harmattan, 2008.

TEPEDINO, Gustavo. A evolução da responsabilidade civil no direito brasileiro e suas controvérsias na atividade estatal. In: . Temas de direito civil. 3. ed. rev. e atual. Rio de Janeiro: Renovar, 2004. p. 191-216.

TEPEDINO, Gustavo. O futuro da responsabilidade civil: editorial. Revista Trimestral de Direito Civil: RTDC, Rio de Janeiro, Padma, v. 6, n. 24, p. iii-v, out./dez. 2005.

THIBIERGE, Catherine. Libres propos sur l'évolution du droit de la responsabilité. Revue Trimestrielle de Droit Civil, n. 3, p. 561-584, juil./sept. 1999.

TOZIER DE LA POTERIE, Arielle; BAUDOIN, Marie-Ange. From Yokohama to Sendai: Approaches to Participation in International Disaster Risk Reduction Frameworks. Internatinal Journal of Disaster Risk Science, n. 6, p. 128-139, 2015. Disponível em: $<$ http://link.springer.com/article/10.1007\%2Fs13753-015-0053-6>. Acesso em: 31 out. 2016.

UNITED NATIONS. Derpartment of Humanitarian Affairs. International Decade for Natural Disaster Reduction (IDNDR). Yokohama strategy and plan of action for a safer world: guidelines for natural disaster prevention, preparedness and mitigation. World Conference on Natural Disaster Reduction. Yokohama, Japão, 23-27 maio 1994. Disponível em $<$ http://www.unisdr.org/files/8241_doc6841 contenido1.pdf $>$. Acesso em: 02 nov. 2016.

UNITED NATIONS. General Assembly. Sendai Framework for Disaster Risk Reduction 2015-2030. A/RES/69/283, New York, 23 June 2015. Disponível em: $<$ https://documentsdds-ny.un.org/doc/UNDOC/GEN/N15/167/16/pdf/N1516716.pdf?OpenElement>. Acesso em: 02 nov. 2016.

UNITED NATIONS. INTERNATIONAL STRATEGY FOR DISASTER REDUCTION (UNISDR). 2009 UNISDR terminology on disaster risk reduction. Geneva, 2009. Disponível em: < http://www.unisdr.org/files/7817_UNISDRTerminologyEnglish.pdf $>$. Acesso em: 20 dez. 2016. 
UNITED NATIONS. INTERNATIONAL STRATEGY FOR DISASTER REDUCTION (UNISDR). Hyogo Framework for Action 2005-2015: building the resilience of nations and communities to disasters. Geneva, 2007. Disponível em:

$<$ http://www.unisdr.org/files/1037_hyogoframeworkforactionenglish.pdf $>$ Acesso em: 02 nov. 2016.

UNITED NATIONS. INTERNATIONAL STRATEGY FOR DISASTER REDUCTION (UNISDR). Living with risk: a global review of disaster reduction initiatives. New York and Geneva, 2004. v. 1. Disponível em: <http://www.unisdr.org/files/657_lwr1.pdf > Acesso em: 02 nov. 2016.

UNITED NATIONS OFFICE FOR DISASTER RISK REDUCTION (UNISDR) = ESCRITÓRIO DAS NAÇÕES UNIDAS PARA A REDUÇÃO DO RISCO DE DESASTRES (UNISDR). Como construir cidades mais resilientes: um guia para gestores públicos locais: uma contribuição à Campanha Global 2010-2015: construindo cidades resilientes: minha cidade está se preparando! Genebra, novembro de 2012. p. 25-58. Disponível em: <http://www.unisdr.org/files/26462_guiagestorespublicosweb.pdf $>$. Acesso em: 02 nov. 2016.

UNITED NATIONS OFFICE FOR DISASTER RISK REDUCTION (UNISDR). Global Assessment Report on Disaster Risk Reduction, 2013. From shared risk to shared value: the business case for disaster risk reduction: globally integrated disasters: supply chain interruption. Disponível em:

$<$ http://www.preventionweb.net/english/hyogo/gar/2013/en/home/GAR_2013/GAR_2013_ 31.html>. Acesso em: 10 out. 2016.

UNITED NATIONS OFFICE FOR DISASTER RISK REDUCTION (UNISDR). Global Assessment Report on Disaster Risk Reduction, 2015. Making development sustainable: the future of disaster risk management. Disponível em:

$<$ http://www.preventionweb.net/english/hyogo/gar/2015/en/gar-pdf/GAR2015_EN.pdf $>$. Acesso em: 20 nov. 2016.

UNITED NATIONS OFFICE FOR DISASTER RISK REDUCTION (UNISDR). Private sector strengths applied: good practices in disaster risk reduction from Japan. 2013.

Disponível em:

$<$ http://www.unisdr.org/files/33594_privatesectorstrengthsapplied2013di.pdf $>$. Acesso em: 02 dez. 2016.

UNITED NATIONS OFFICE FOR DISASTER RISK REDUCTION (UNISDR). Reading the Sendai Framework for Action 2015-2030. Geneva, 2015. Disponível em: $<$ http://www.preventionweb.net/files/46694_readingsendaiframeworkfordisasterri.pdf $>$. Acesso em: 20 out. 2016.

UNITED NATIONS OFFICE FOR DISASTER RISK REDUCTION (UNISDR). What is disaster risk reduction? Disponível em: <http://www.unisdr.org/who-we-are/what-is-drr>. Acesso em: 10 out. 2016.

UNITED STATES. Department of Homeland Security. FEMA: prepared, responsive, committed. FEMA B-653 / July 2008. Disponível em:

$<$ https://www.fema.gov/pdf/about/brochure.pdf> Acesso: 09 out. 2016. 
VARELA, João de Matos Antunes. Das obrigações em geral. 10. ed. rev. e atual. 2. reimpr. Coimbra: Almedina, 2004. v. 1.

VIANNA, José Ricardo Alvarez. Responsabilidade civil por danos ao meio ambiente. 2. ed. rev. e atual., reimpr. Curitiba: Juruá, 2010.

VILLEY, Michel. Esboço histórico sobre o termo responsável (1977). Tradução de André Rodrigues Corrêa. Revista Direito GV, São Paulo, Fundação Getulio Vargas, v. 1, n. 1, p. 135-148, maio 2005.

VINEY, Geneviève. Traité de droit civil: introduction à la responsabilité. 3e éd. Paris: LGDJ, 2008.

VINEY, Geneviève; JOURDAIN, Patrice. Traité de droit civil: les effets de la responsabilité. 3e éd. Paris: LGDJ, 2010.

VOLTAIRE. Poème sur le désastre de Lisbonne, 1756= O poema sobre o desastre de Lisboa. Tradução de Vasco Graça Moura. Lisboa: Alêtheia Editores, 2013. 